\title{
Vadim Nikolaevich Tsytovich \\ (In Honor of His 80th Birthday)
}

PACS numbers: $01.30 .+\mathrm{q}$

DOI: $10.1134 / \mathrm{S} 1063780 \mathrm{X} 09080121$

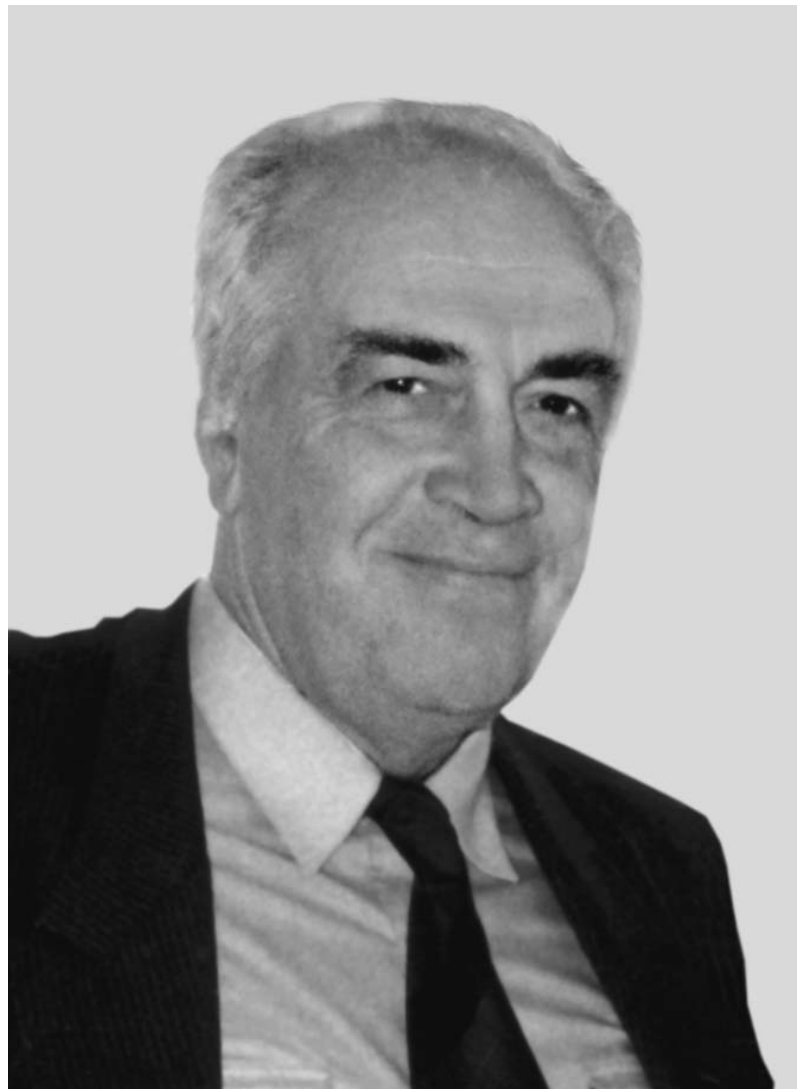

March 17, 2009, was the 80th birthday of Vadim Nikolaevich Tsytovich.
Tsytovich is an eminent scientist and exceptional man, with a life full of achievements and many years of creative work.

Science has been an integral part of his life. After graduating from the Physical Department of Moscow State University in 1949, he worked in various fields of physics, such as quantum physics, astrophysics, and plasma physics.

Tsytovich worked with V.I. Veksler, V.L. Ginzburg, S.A. Kaplan, and S.B. Pikel'ner. He has collaborated with many physical institutes, universities, and scientific laboratories in Russia and abroad and is continuing to work on joint projects

Tsytovich has written dozens of books, monographs, and reviews. He has mentored many highly qualified scientists, who are presently working at leading scientific centers all over the world. His course of lectures on plasma physics has been recognized as classic.

Tsytovich is a man of great erudition. He is perfectly acquainted with modern problems of physics and the most recent theoretical methods. His work on plasma physics, radiation theory, methods for particle acceleration, quantum electrodynamics, and others issues has received worldwide recognition.

Tsytovich remains vigorous and active in both his scientific research and private life. He likes to travel and engage in sports.

The friends and colleagues of Vadim Nikolaevich heartily congratulate him on his birthday and wish him robust health, further scientific achievements, and the strength to remain vigorous and active for many years to come. 